\title{
Right heart size and function significantly correlate in patients with pulmonary arterial hypertension - a cross-sectional study
}

\author{
Lukas Fischer ${ }^{1}$, Nicola Benjamin ${ }^{1,2}$, Norbert Blank ${ }^{3}$, Benjamin Egenlauf ${ }^{1,2}$, Christine Fischer $^{4}$, Satenik Harutyunova ${ }^{1,2}$, \\ Maria Koegler ${ }^{1}$, Hanns-Martin Lorenz ${ }^{3}$, Alberto M. Marra ${ }^{1,2,5}$, Christian Nagel ${ }^{1,2,6}$, Panagiota Xanthouli $i^{1,2}$, \\ Eduardo Bossone ${ }^{7}$ and Ekkehard Grünig ${ }^{1,2^{*}}$
}

\begin{abstract}
Background: The objective of this study was to assess, whether right atrial (RA) and ventricular (RV) size is related to RV pump function at rest and during exercise in patients with pulmonary arterial hypertension (PAH).

Methods: We included 54 patients with invasively diagnosed PAH that had been stable on targeted medication. All patients underwent clinical assessments including right heart catheterization and echocardiography at rest and during exercise. RV output reserve was defined as increase of cardiac index (Cl) from rest to peak exercise $\left(\Delta C l_{\text {exercise }}\right)$. Patients were classified according to the median of RA and RV-area. RV pump function and further clinical parameters were compared between groups by student's t-test. Uni- and multivariate Pearson correlation analyses were performed.
\end{abstract}

Results: Patients with larger RA and/or RV-areas (above a median of 16 and $20 \mathrm{~cm}^{2}$, respectively) showed significantly lower $\Delta \mathrm{Cl}_{\text {exercise, }}$ higher mean pulmonary arterial pressure, pulmonary vascular resistance at rest and NT-proBNP levels. Furthermore, patients with higher RV-areas presented with a significantly lower RV stroke volume and pulmonary arterial compliance at peak exercise than patients with smaller RV-size. RV area was identified as the only independent predictor of RV output reserve.

Conclusion: RV and RA areas represent valuable and easily accessible indicators of RV pump function at rest and during exercise. Cardiac output reserve should be considered as an important clinical parameter. Prospective studies are needed for further evaluation.

Keywords: Pulmonary hypertension, Right ventricular output reserve, Pump function, Right ventricular size, Right atrial size

\section{Background}

Pulmonary arterial hypertension $(\mathrm{PAH})$ is a complex cardiopulmonary disorder, characterized by progressive changes affecting both the pulmonary vasculature and the right heart $[1,2]$. Although the initial pathological changes occur on pulmonary arterioles causing increased

\footnotetext{
* Correspondence: ekkehard.gruenig@med.uni-heidelberg.de

${ }^{1}$ Centre for Pulmonary Hypertension, Thoraxklinik at Heidelberg University Hospital, Röntgenstrasse 1, D-69126 Heidelberg, Germany

${ }^{2}$ Translational Lung Research Center Heidelberg (TLRC), Member of the

German Center for Lung Research (DZL), Heidelberg, Germany

Full list of author information is available at the end of the article
}

pulmonary vascular resistance (PVR), adaptation of right ventricular (RV) pump function is a key determinant of survival $[2,3]$. Rising attention is drawn to the concept of $\mathrm{RV}$-arterial coupling, a composite measure of RV pump function and ventricular load [4-6].

Right atrial (RA) [7-9] and RV size have repeatedly been proven of prognostic significance in pulmonary hypertension $[2,10]$, whereas their impact on RV contractility remains to be determined. Recent studies using magnetic resonance imaging (MRI) have shown, that increased RV-endsystolic or diastolic volumes were significantly related to a worse outcome and reduced RV stroke volume 
(SV) [11]. In a further study enlargement of RV volumes during follow-up was associated with further clinical signs of disease progression [12].

$\mathrm{RV}$ output reserve $\left(\Delta \mathrm{Cl}_{\text {exercise }}\right)$ defined as increase of cardiac output/cardiac index (CI) during exercise with normal or elevated PVR measured by right heart catheterization (RHC) is an emerging parameter which has shown to be prognostically important in patients with $\mathrm{PAH}[13,14]$. It solely displays the capacity of the right ventricle to adjust its systolic function to a given level of pulmonary loading ${ }^{4}$. Pulmonary arterial compliance (PAC) reflects the elasticity of the pulmonary arteries. For estimation of pulmonary arterial compliance (or capacitance) the measurement of $\mathrm{SV} /$ pulse pressure (cardiac output/heart rate)/(systolicPAPdiastolicPAP) by RHC has been shown to be the most simple and practical method $[15,16]$.

The objective of the study was to investigate the correlation between right heart size (measured as right atrial and ventricular area by echocardiography) and RV pump function at rest and during exercise (assessed by RHC) and further hemodynamic and clinical parameters. Furthermore, this study aimed to detect correlations and determining factors of RV pump function.

\section{Methods}

\section{Patient selection}

We retrospectively reviewed all incident (i.e. newly diagnosed) patients aged $\geq 18$ to 80 years with idiopathic, heritable or drug- and toxin-induced or connective tissue disease associated PAH who were diagnosed at the $\mathrm{PH}$-center in Heidelberg between January 1st, 2016 and November 31st, 2016. Inclusion required $\mathrm{RHC}$ at rest (confirming PAH, defined as a mean pulmonary arterial pressure $\geqslant 25 \mathrm{mmHg}$, pulmonary arterial wedge pressure $\leqslant 15 \mathrm{mmHg}$ and PVR $>3$ Wood units [17], and during exercise. Diagnosis of $\mathrm{PAH}$ was performed according to the ESC/ERS guidelines [17].

Patients were excluded if they lacked a complete evaluation including medical history, WHO/NYHA functional class assessment, physical examination, electrocardiogram, transthoracic 2D-echocardiography at rest, lung function test, arterial blood gases, 6-min walking distance (6MWD) under standardized conditions [18], laboratory testing including NT-proBNP levels. All examinations were performed at the Thoraxklinik at Heidelberg University Hospital by experienced physicians within $48 \mathrm{~h}$ from the right heart catheterization.

\section{Right heart catheterization}

The hemodynamic values have been obtained by the charts. The right heart catheterization has been performed in a standardized way in a supine position using the transjugular access with a triple-lumen 7F-Swan-Ganz thermodilution catheter at rest and during exercise as previously described [19]. Patients had been examined on a variable load supine bicycle ergometer by experienced investigators $(\mathrm{CN}, \mathrm{BE}, \mathrm{SH})$. Pressures were continuously recorded and averaged over several respiratory cycles during spontaneous breathing, both at rest and during exercise. Cardiac output $(\mathrm{CO})$ was measured by thermodilution at least in triplicate with a variation of less than $10 \%$ between the measured values. The zero reference point for pressure recordings was set at $1 / 2$ of the thoracic diameter below the anterior thorax surface [20]. After the hemodynamic measurement at rest, the supine position was changed to a $45^{\circ}$ position. Calibration for exercise measurements were performed as previously described [21]. The exercise test was started with a workload of $25 \mathrm{~W}$. Workload was incrementally increased by $25 \mathrm{~W}$ every 2 min to an exercise capacity or symptom limited maximum.

\section{Echocardiography}

Resting two dimensional transthoracic echocardiography (TTE) Doppler examinations were performed by experienced cardiac sonographers (EG, $\mathrm{CN}, \mathrm{BE}, \mathrm{SH}$ ) with commercially available equipment (Vivid 7, GE Healthcare, Milwaukee, Wisconsin) according to standardized protocol as described previously $[9,22]$. TTE measurements were obtained off line from stored DICOM data according to the European Association of Cardiovascular Imaging (EACVI) Guidelines [23]. Specific indices included RA-/RV-area, TAPSE and PASP at rest. For all calculations the mean value of at least 3 measurements was used. PASP was estimated from peak tricuspid regurgitation jet velocities (TRV) according to the equation: $\mathrm{PASP}=4(\mathrm{~V})[2]+$ right atrial pressure, where $\mathrm{V}$ is the peak velocity (in $\mathrm{m} / \mathrm{s}$ ) of tricuspid regurgitation jet (TRV) [24]. Right atrial pressure was estimated from characteristics of the inferior vena cava [18]. If it was $<20 \mathrm{~mm}$ in diameter and decreased during inspiration we added $5 \mathrm{mmHg}$, $\geq 20 \mathrm{~mm}$ we added $10 \mathrm{mmHg}$ and $15 \mathrm{mmHg}$ if no decrease of diameter during inspiration occurred.

\section{Cardiopulmonary exercise testing}

Patients were examined on a variable load supine bicycle ergometer (model 8420; KHL Corp., Kirkland, Washington) in Heidelberg as described previously [25]. Workload was increased by $25 \mathrm{~W}$ every 2 min to an exercise capacity or symptom limited maximum. Peak $\mathrm{VO}_{2}$ was defined as the highest 30-s average value of oxygen uptake during the last minute of the exercise test. 


\section{Ethics statement}

The Ethics Committee of the Medical Faculty, University of Heidelberg had no obligation against the conduct of the study (internal number S425/2016). All data were anonymized and the study was conducted in accordance with the amended Declaration of Helsinki.

\section{Statistical methods}

Statistical analyses were conducted by two biometricians (CF, NE). Data are described as means \pm standard deviations or number and respective percentage. Patients were divided into two groups according to their RV size (larger or smaller RA and/or RV area with value above or below the median of the complete sample). A receiver operating characteristic (ROC) curve analysis for RA and RV area with $\mathrm{CI}$ increase below the median of the sample as outcome parameter for further validation of the cut-off values was performed. Quantitative characteristics between the two groups including demographics, hemodynamics and parameters of echocardiography and cardiopulmonary exercise testing were compared by two-sided student's t-tests and nonparametric tests if needed. Frequency distributions were compared by chi-square test or Fisher's exact test. A sensitivity analysis with a threshold of $18 \mathrm{~cm}^{2}$ for RV area according to the cut-off proposed by the guidelines ${ }^{17}$ was performed.

Right heart size (RA and RV area) was compared between patients with higher vs. lower $\Delta \mathrm{CI}_{\text {exercise }}$ (according to the median of the complete sample).

Differences of the course of $\mathrm{CI}$ and SV increase during exercise between patients with smaller vs. larger RA and RV area were analysed with mixed ANOVA. To investigate the associations between clinical parameters, right heart size and output reserve, Pearson's correlation analysis was performed. To identify independent predictors of RV output reserve, multivariate analysis was performed by stepwise forward selection method of logistic regression with the dichotomous variable of the two groups (high or low $\Delta \mathrm{CI}_{\text {exercise }}$ ) as outcome variable. Parameters for correlation analysis included demographics, hemodynamics, echocardiographic parameters and measures of cardiopulmonary exercise testing according to clinical significance.

Pulmonary arterial compliance (PAC) was calculated according the formula $\mathrm{PAC}=\mathrm{SV} /$ pulse pressure with $\mathrm{SV}=\mathrm{CO} /$ Heart rate and pulse pressure $=\mathrm{sPAP}-\mathrm{dPAP}$. Stroke volume index was calculated with $\mathrm{SVI}=\mathrm{CI} /$ heart rate.

All tests were two-sided and a pointwise $p$-value of 0.05 was considered statistically significant. All analyses have been performed using IBM SPSS 23 (SPSS Statistics V23, IBM Corporation, Somers, New York).

\section{Results}

Study population (Table 1)

We included 54 patients diagnosed with moderate to severe $\mathrm{PAH}$ who fulfilled the inclusion criteria (21 males and 33 females, mean age $53 \pm 15$ years, $66.7 \%$ WHO functional class II, 57.4\% double combination therapy; Table 1).

The study cohort presented with a median RA of $16 \mathrm{~cm}^{2}$ and RV of $20 \mathrm{~cm}^{2}$. ROC curve analysis for RA and RV area with CI increase $<2.1 \mathrm{l} / \mathrm{min} / \mathrm{m}^{2}$ (median of the sample for CI increase) further supported these proposed cutoff-values of $16 \mathrm{~cm}^{2}$ for RA and $20 \mathrm{~cm}^{2}$ for RV area (Fig. 1). For RV area, $20 \mathrm{~cm}^{2}$ showed a sensitivity of $75 \%$ and specificity of $73.1 \%$; an RA area of $16 \mathrm{~cm}^{2}$ presented with a sensitivity of $75 \%$ and specificity of $57.7 \%$.

Characteristics of groups with small and large right heart size: According to the median RA and RV area, two subgroups were defined for both RA and RV area: 1) "enlarged right heart size" (RA $>16 \mathrm{~cm}^{2}, \mathrm{RV}>20 \mathrm{~cm}^{2}$ ) and 2) "normal/smaller right heart size" (RA $\leq 16 \mathrm{~cm}^{2}$, $\mathrm{RV} \leq 20 \mathrm{~cm}^{2}$; Table 2).

Both groups did not significantly differ in their demographics (age and BMI), 6MWD, diffusion capacity and peak $\mathrm{VO}_{2}$ for both RA and $\mathrm{RV}$ area. $\mathrm{PH}$-targeted treatment and distribution of combination treatment did also not significantly differ between groups (Table 2).

Patients with enlarged RA- $(n=21)$ and/or RV-area $(n=24)$ had significantly higher mean, systolic and diastolic pulmonary arterial pressures, mean pulmonary vascular resistance, and NT-proBNP levels than patients with normal or smaller right heart size.

Both groups of RA and RV size had well preserved $\mathrm{RV}$ function at rest, represented by regular CI and SV, even though PVR and mean pulmonary arterial pressures were elevated in patients with enlarged right heart size. Increase of CI during exercise was significantly smaller in patients with enlarged RA- or RV-areas (Fig. 2a and b). Furthermore, patients with higher RV-area, but not RA-area, presented with a significantly lower SV, SVI and pulmonary arterial compliance at peak exercise than patients with smaller RV-size (Table 2).

SV failed to increase in accordance with the exposed exercise level in patients with large RA$(p=0.031)$ and/or RV area $(p<0.001$; Fig. 3). Likewise, SVI was significantly higher in patients with small right heart size, compared to patients with enlarged RA and/or RV area (ANOVA RV $\mathrm{p}<0.001$, RA $p=0.001)$. Furthermore, patients with smaller $\mathrm{RV}$, but not RA, presented with significantly higher peak PAC than patients with RV area above the median $(39.5 \pm 11.2 \mathrm{ml} / \mathrm{mmHg}$ vs. $33.2 \pm 15.3 \mathrm{ml} / \mathrm{mmHg}$, $p=0.027)$. 
Table 1 Characteristics of the study population

\begin{tabular}{|c|c|c|c|c|c|c|}
\hline \multirow{2}{*}{\multicolumn{2}{|c|}{ Demographics }} & \multirow[b]{2}{*}{ Age } & \multirow[b]{2}{*}{ (years) } & \multicolumn{3}{|c|}{ mean \pm SD or $n(\%)$} \\
\hline & & & & 53 & \pm & 14.65 \\
\hline & & BMI & $\left(\mathrm{kg} / \mathrm{m}^{2}\right)$ & 27.9 & \pm & 5.69 \\
\hline \multirow{2}{*}{\multicolumn{2}{|c|}{ Gender }} & male & $n(\%)$ & 21 & & $(38.9)$ \\
\hline & & female & $n(\%)$ & 33 & & $(61.1)$ \\
\hline \multirow{4}{*}{\multicolumn{2}{|c|}{ Diagnosis }} & IPAH & $n(\%)$ & 31 & & $(57.4)$ \\
\hline & & $\mathrm{HPAH}$ & $n(\%)$ & 8 & & $(14.8)$ \\
\hline & & APAH & $n(\%)$ & 12 & & $(22.2)$ \\
\hline & & CTEPH & $n(\%)$ & 3 & & $(5.6)$ \\
\hline \multirow{3}{*}{\multicolumn{2}{|c|}{ WHO functional class }} & I & $n(\%)$ & 1 & & $(1.9)$ \\
\hline & & $\|$ & $n(\%)$ & 36 & & $(66.7)$ \\
\hline & & III & $n(\%)$ & 17 & & $(31.5)$ \\
\hline \multirow{5}{*}{\multicolumn{2}{|c|}{ PAH-targeted medication }} & \multicolumn{2}{|c|}{ Endothelin receptor antagonist } & 40 & & $(74.1)$ \\
\hline & & \multicolumn{2}{|c|}{ Phosphodiesterase-5-inhibitors } & 38 & & $(70.4)$ \\
\hline & & \multicolumn{2}{|c|}{ Soluble guanylate cyclase-stimulator } & 8 & & $(13.0)$ \\
\hline & & \multicolumn{2}{|l|}{ Prostanoids } & 6 & & $(14.8)$ \\
\hline & & \multicolumn{2}{|c|}{ Calcium channel blockers } & 2 & & (03.7) \\
\hline \multicolumn{7}{|l|}{ Combination therapy } \\
\hline & & Mono & $n(\%)$ & 18 & & (33.3) \\
\hline & & Double & $n(\%)$ & 31 & & $(57.4)$ \\
\hline & & Triple & $n(\%)$ & 5 & & $(9.3)$ \\
\hline \multirow[t]{17}{*}{ RHC } & Rest & mPAP & $(m m H g)$ & 35.5 & \pm & 11.69 \\
\hline & & SPAP & $(m m H g)$ & 57.6 & \pm & 20.87 \\
\hline & & dPAP & $(\mathrm{mmHg})$ & 23 & \pm & 7.87 \\
\hline & & PCWP & $(m m H g)$ & 10 & \pm & 3.54 \\
\hline & & PVR & $\left(d y n^{*} \sec ^{*} \mathrm{~cm}^{-5}\right)$ & 393.4 & \pm & 235.03 \\
\hline & & $\mathrm{CO}$ & $(1 / \min )$ & 5.8 & \pm & 1.61 \\
\hline & & $\mathrm{Cl}$ & $\left(1 / \mathrm{min} / \mathrm{m}^{2}\right)$ & 3 & \pm & 0.73 \\
\hline & & SVI & $\left(\mathrm{m} / / \mathrm{m}^{2}\right)$ & 41.1 & \pm & 10.2 \\
\hline & $25 \mathrm{~W}$ & $\triangle \mathrm{Cl}$ & $\left(1 / \mathrm{min} / \mathrm{m}^{2}\right)$ & 1.2 & \pm & 0.67 \\
\hline & $50 \mathrm{~W}$ & $\Delta \mathrm{Cl}$ & $\left(1 / \mathrm{min} / \mathrm{m}^{2}\right)$ & 2 & \pm & 0.93 \\
\hline & $75 \mathrm{~W}$ & $\Delta \mathrm{Cl}$ & $\left(1 / \mathrm{min} / \mathrm{m}^{2}\right)$ & 2.6 & \pm & 1.15 \\
\hline & Peak & mPAP & $(m m H g)$ & 56.5 & \pm & 15.91 \\
\hline & & SPAP & $(\mathrm{mmHg})$ & 90.2 & \pm & 28.36 \\
\hline & & dPAP & $(m m H g)$ & 36.1 & \pm & 11.56 \\
\hline & & $\mathrm{CO}$ & $(1 / \mathrm{min})$ & 10.2 & \pm & 3.49 \\
\hline & & $\mathrm{Cl}$ & $\left(1 / \mathrm{min} / \mathrm{m}^{2}\right)$ & 5.3 & \pm & 1.59 \\
\hline & & SVI & $\left(\mathrm{m} / / \mathrm{m}^{2}\right)$ & 47.2 & \pm & 13.9 \\
\hline \multirow{3}{*}{\multicolumn{2}{|c|}{ Echocardiography }} & $\mathrm{RV}$ area & $\left(\mathrm{cm}^{2}\right)$ & 20.1 & \pm & 5.59 \\
\hline & & RA area & $\left(\mathrm{cm}^{2}\right)$ & 16.8 & \pm & 6.62 \\
\hline & & TAPSE & $(\mathrm{cm})$ & 2.3 & \pm & 0.38 \\
\hline \multirow{4}{*}{\multicolumn{2}{|c|}{$\begin{array}{l}\text { Cardiopulmonary exercise } \\
\text { testing (CPET) }\end{array}$}} & peak $V^{\prime} \mathrm{O}_{2}$ & $(\mathrm{ml} / \mathrm{min})$ & 1126 & \pm & 428.88 \\
\hline & & peak $V^{\prime} \mathrm{O}_{2} / \mathrm{kg}$ & $(\mathrm{ml} / \mathrm{min} / \mathrm{kg})$ & 14.1 & \pm & 3.92 \\
\hline & & SPAP Max & $(m m H g)$ & 81.8 & \pm & 27.87 \\
\hline & & 6-MWD & $(m)$ & 423 & \pm & 113.09 \\
\hline
\end{tabular}


Table 1 Characteristics of the study population (Continued)

\begin{tabular}{|c|c|c|c|c|c|}
\hline \multirow[b]{2}{*}{ Laboratory analysis } & \multirow[b]{2}{*}{ NT-proBNP } & \multirow[b]{2}{*}{$(\mathrm{pg} / \mathrm{ml})$} & \multicolumn{3}{|c|}{ mean \pm SD or $n(\%)$} \\
\hline & & & 470.3 & \pm & 856.74 \\
\hline \multirow[t]{2}{*}{ Pulmonary function test (PFT) } & DLCOc SB & (\% Soll) & 58.6 & \pm & 17.25 \\
\hline & DLCOC VA & (\% Soll) & 70.42 & \pm & 20.00 \\
\hline
\end{tabular}

$I P A H=$ idiopathic pulmonary arterial hypertension, $H P A H=$ heritable $\mathrm{PAH}, A P A H=$ associated $\mathrm{PAH}, \mathrm{CTEPH}=$ chronic thromboembolic $\mathrm{PH}, \mathrm{RHC}=$ right heart catheter $B M I=$ Body Mass Index, $R V=$ right ventricular, $\mathrm{RA}=$ right atrial, TAPSE = tricuspid annular plane systolic excursion, $V O_{2}^{\prime}=$ oxygen $^{\prime}$ consumption, $N T$-proBNP $=\mathrm{N}-$ terminal pro brain natriuretic peptide, $D L C O C S B=$ diffusing capacity transfer factor, $D L C O C / V A=$ diffusing capacity transfer coefficient, mPAP = mean pulmonary arterial pressure, $s P A P=$ systolic $P A P, d P A P=$ diastolic $P A P, P C W P=$ pulmonary capillary wedge pressure, $P V R=$ pulmonary vascular resistance, $C l=C$ ardiac Index, $S V I=$ stroke volume index,$H R=$ heart rate, $S V=$ stroke volume, $\Delta=$ difference

Sensitivity analysis with a threshold of $18 \mathrm{~cm}^{2}$ for $\mathrm{RV}$ area led to the same differences between groups with small and large right heart size. Furthermore, CI increase showed a statistically significant difference for each workload level.

When dichotomising the patient cohort according to $\mathrm{RV}$ output reserve (high and low $\Delta \mathrm{CI}_{\text {exercise }}$ ) echocardiography showed considerable differences in RV and RA area $(p=0.003$ and $p=0.019$ respectively; Fig. $4 \mathrm{a}$ and $\mathrm{b})$.

\section{Factors associated with right heart size and RV output reserve (Tables 3 and 4)}

Univariate analysis of right heart size and output reserve In univariate regression analysis $R V$ and $R A$ area were significantly correlated with NT-proBNP, sPAP, CI during exercise, $\Delta \mathrm{CI}_{\text {Peak }}$ (Fig. 5) and with right heart size (Table 3 ). RV area additionally significantly correlated with mPAP at rest, $\mathrm{CI}$ at rest, PVR at rest and peak mPAP.
$\Delta \mathrm{CI}_{\text {exercise }}$ significantly positively correlated with age, exercise capacity (6-MWD, peak oxygen consumption, peak oxygen consumption $/ \mathrm{kg} / \mathrm{min})$, hemodynamics $(\mathrm{CO}$ at rest; peak $\mathrm{CO}$ and $\mathrm{CI}$ during exercise) and lung diffusing capacity (transfer factor DLCOc SB and transfer coefficient DLCOc / VA) (Table 4). A negative correlation was detected between $\Delta \mathrm{CI}_{\text {exercise }}$ and NT-proBNP, echocardiographic parameters (sPAP, RA area, RV area) and hemodynamics at rest (mPAP, PVR).

Multivariate analysis of output reserve Stepwise forward selection of multivariate logistic regression analysis showed RV area to be the single independent predictor for high or low $\Delta \mathrm{CI}_{\text {Peak }}$ (regression coefficient $0.863, p=0.027$ ).

\section{Discussion}

To the best of our knowledge this is the first study showing that in patents with PAH enlarged RV- or

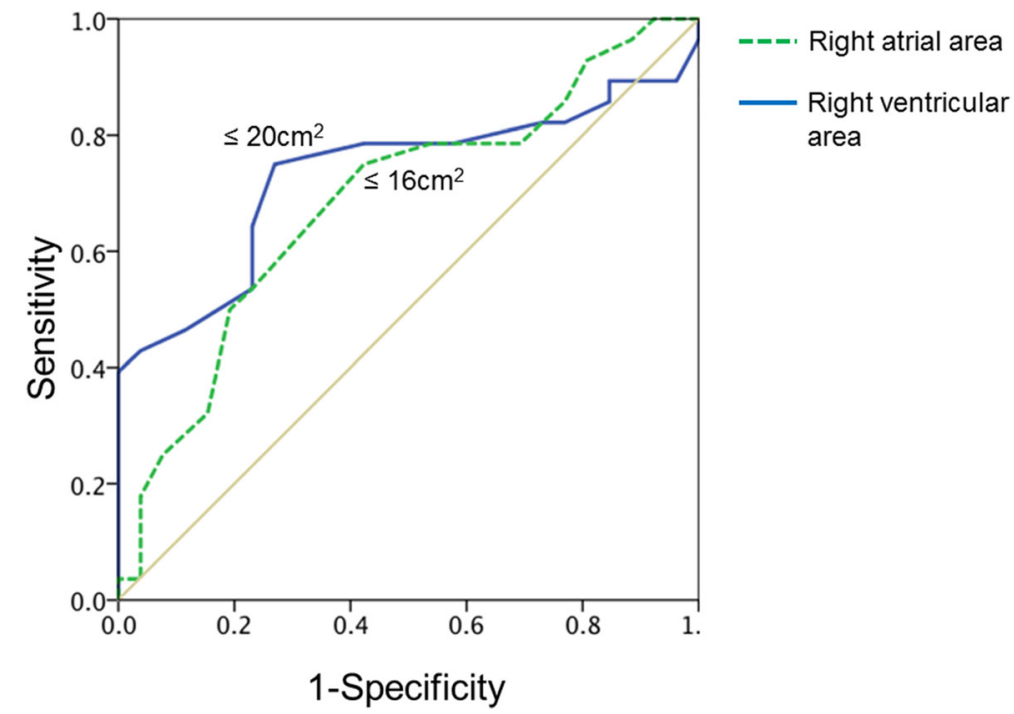

Fig. 1 ROC curve analysis. For RV area, $20 \mathrm{~cm}^{2}$ showed a sensitivity of $75 \%$ and specificity of $73.1 \%$; an RA area of $16 \mathrm{~cm}^{2}$ presented with a sensitivity of $75 \%$ and specificity of $57.7 \%$ 


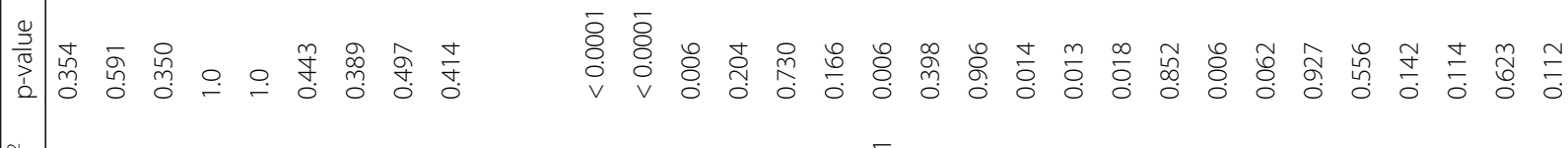

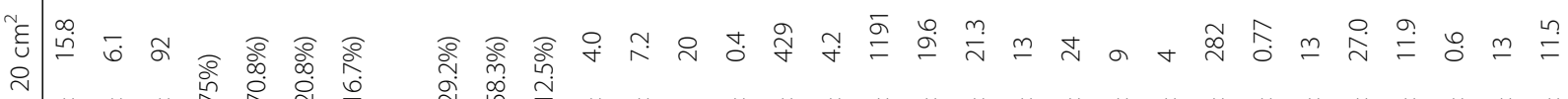

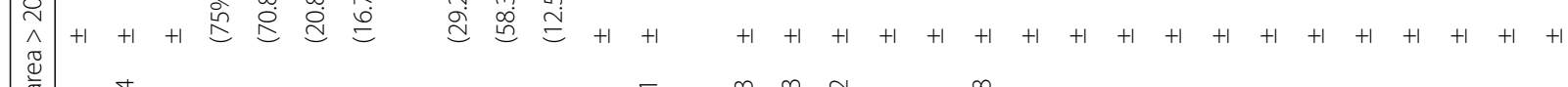

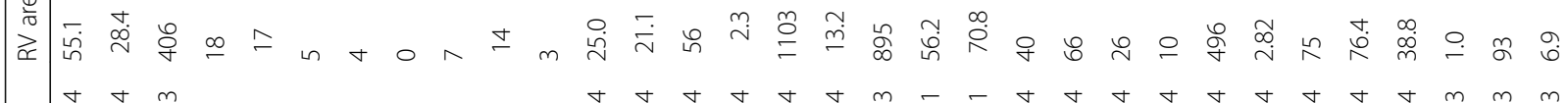

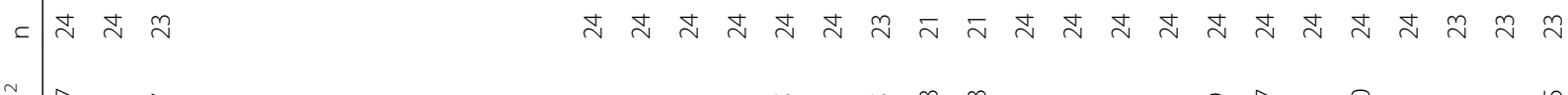

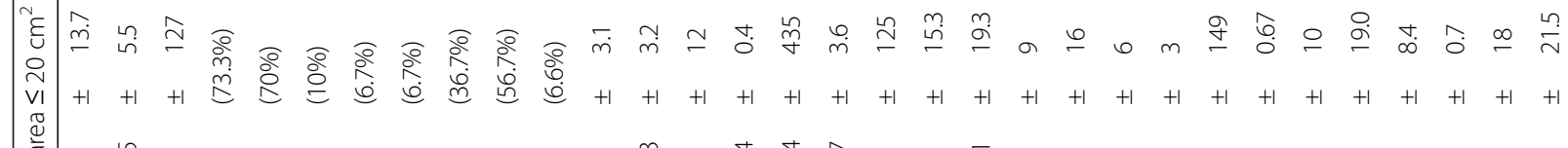

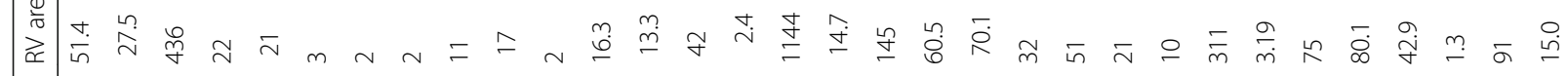

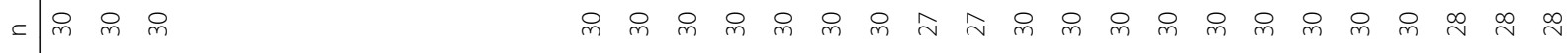

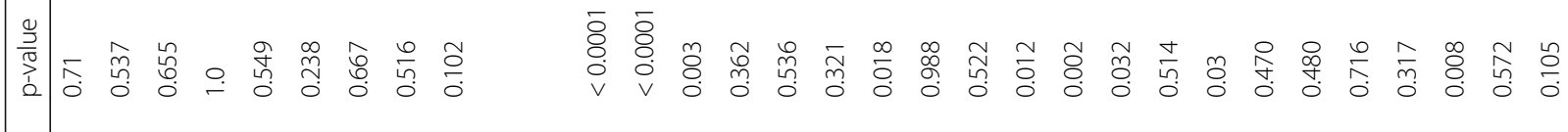

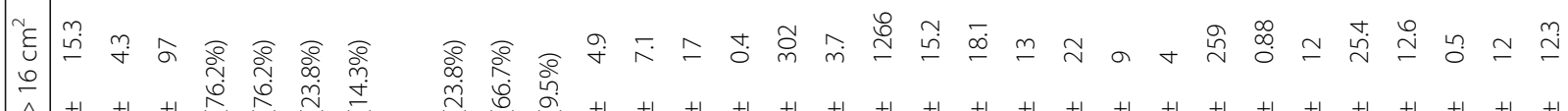

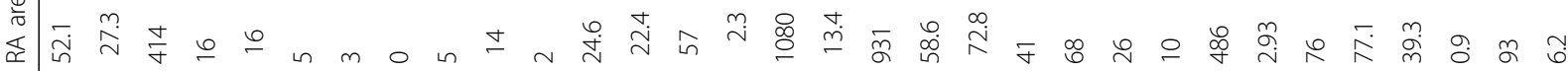

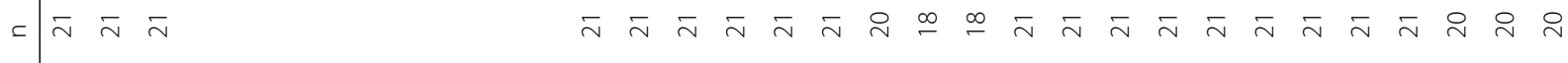

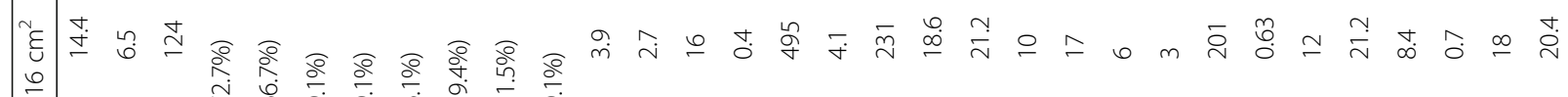

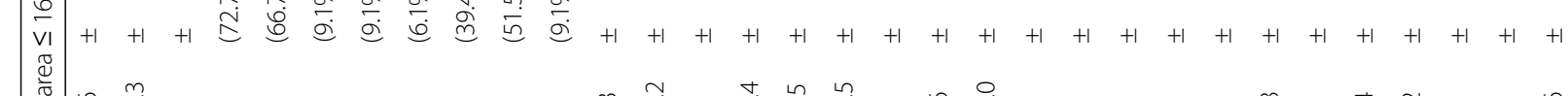

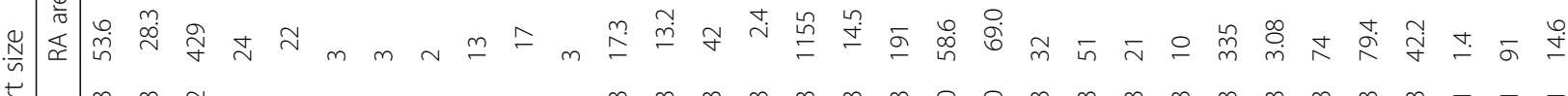

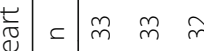
$m m m m m m m p \infty m m m m m m m m m \bar{m} \bar{m} \bar{m} \bar{m}$

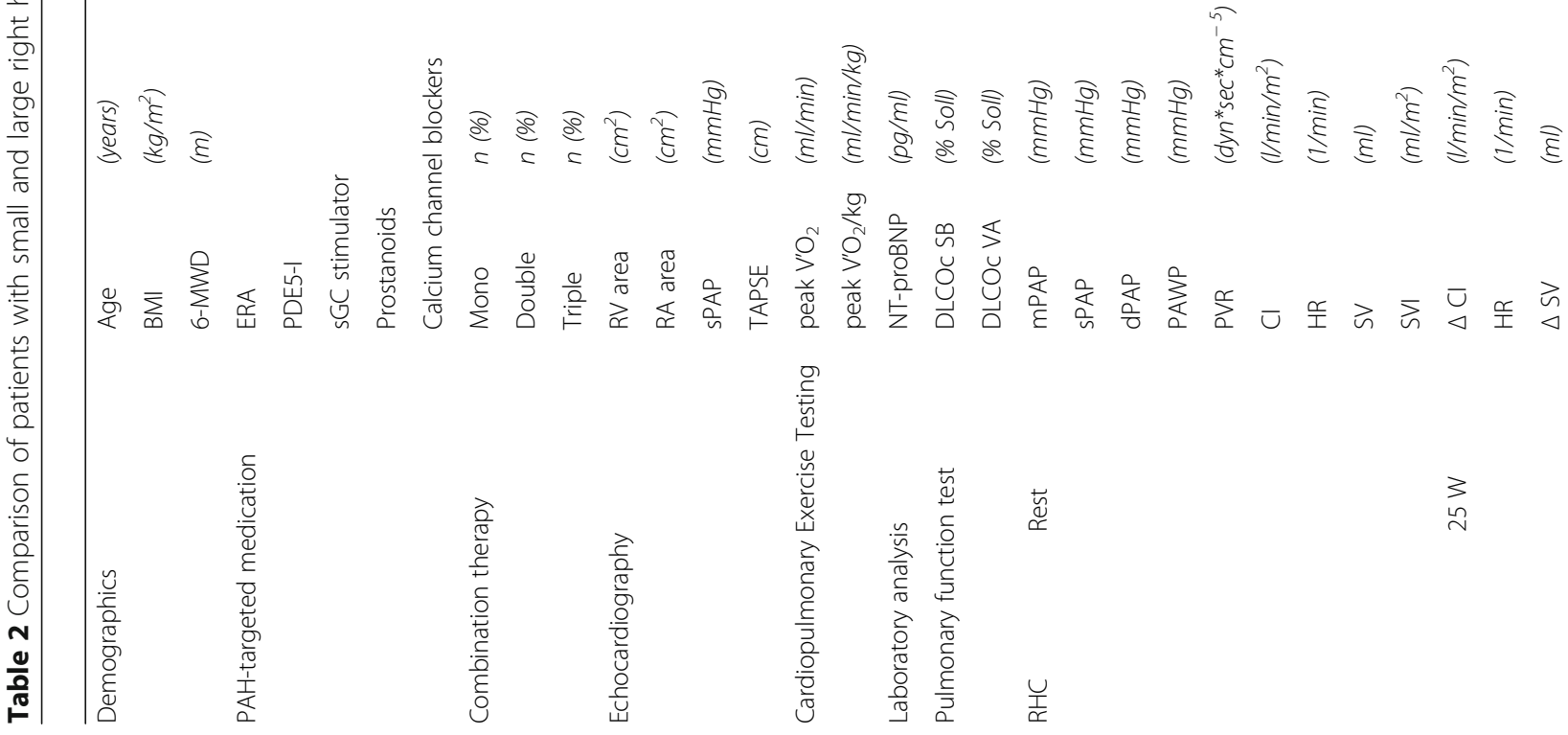




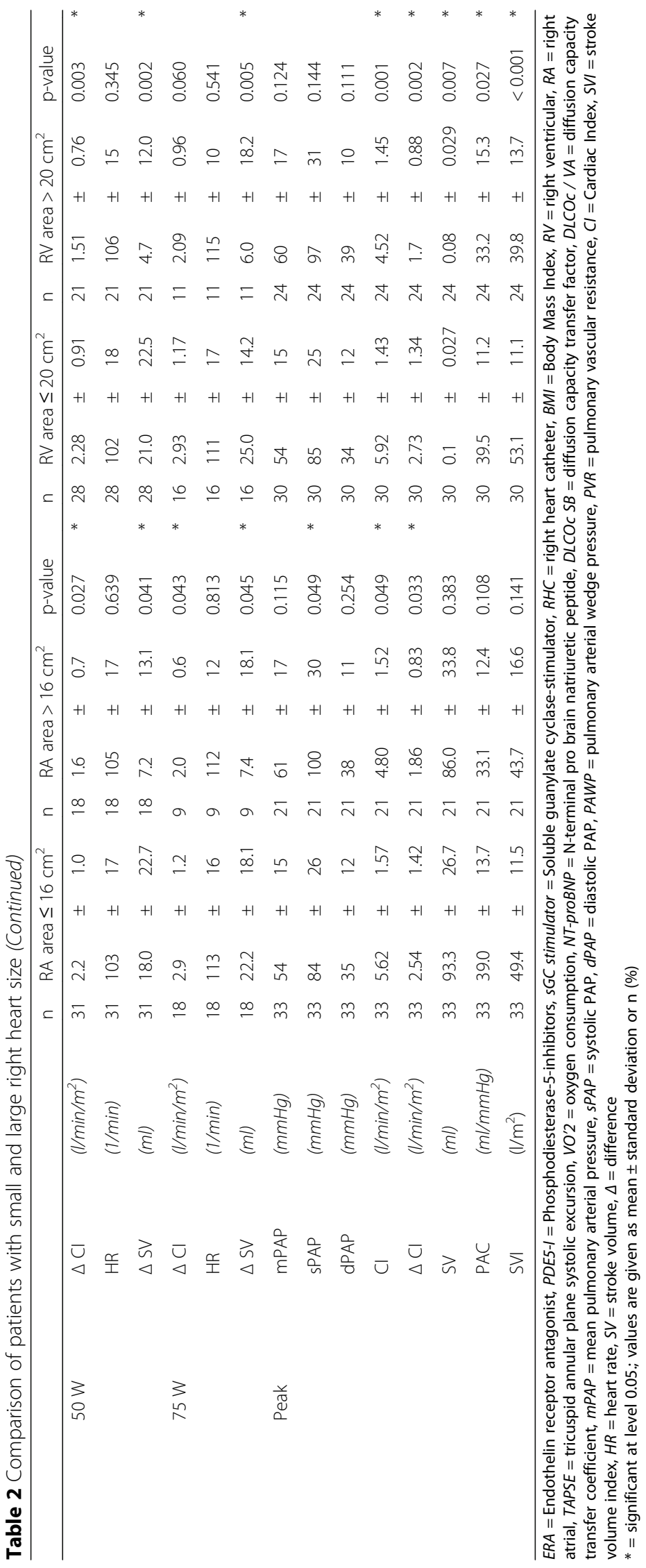




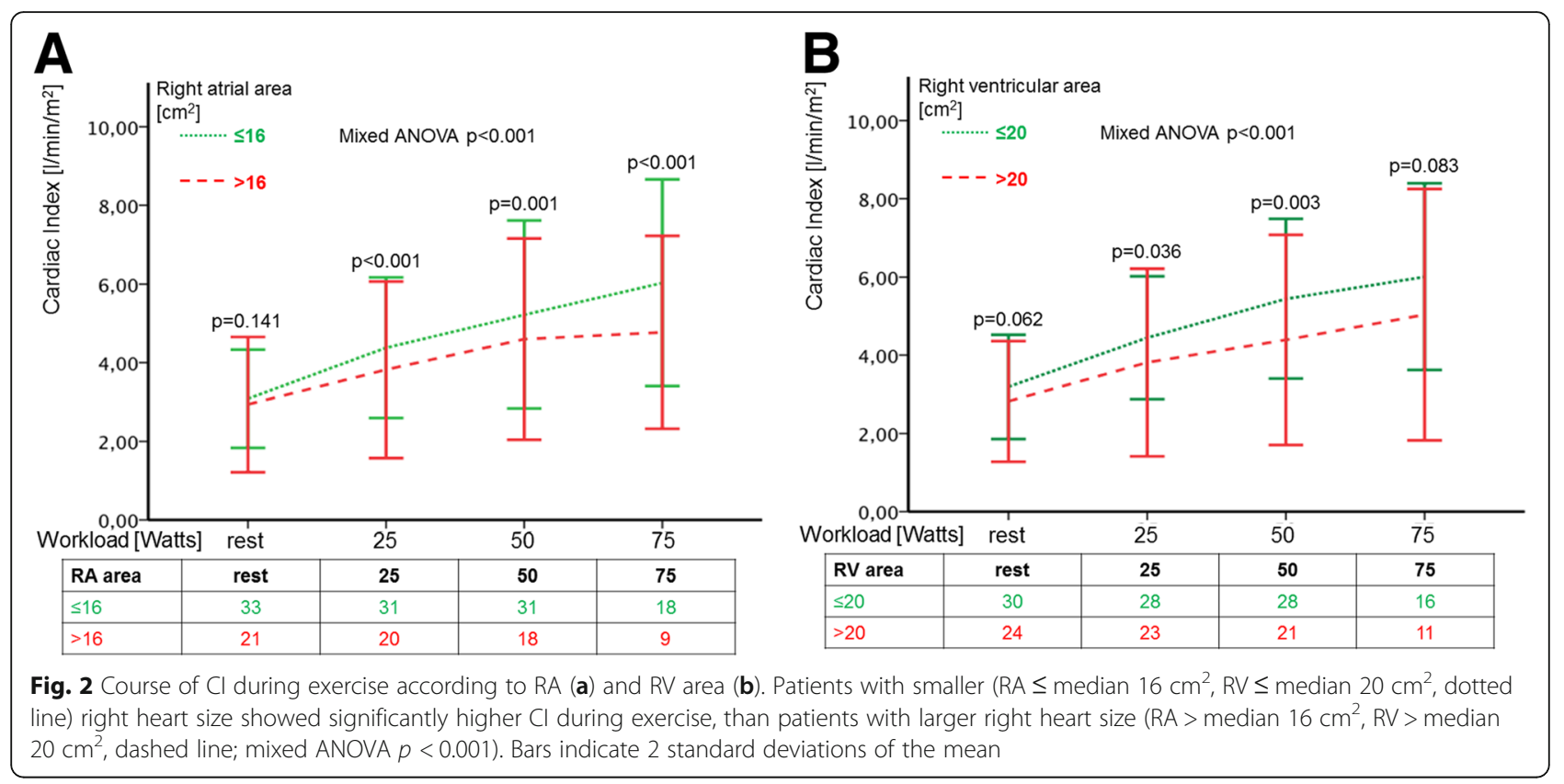

RA areas (measured by echocardiography) were associated with a significantly reduced RV pump function during exercise (lower $\Delta \mathrm{CI}_{\text {exercise }}$ ) measured by right heart catheterization. Furthermore, the study revealed that PAH-patients with larger size of the right heart had higher pulmonary arterial pressures, pulmonary vascular resistance and NT-proBNP levels.
Patients with higher RV-areas presented with a significantly lower stroke volume index and pulmonary arterial compliance at peak exercise than patients with smaller RV-size. RV area was identified as the only independent predictor of RV output reserve (lower $\left.\Delta \mathrm{CI}_{\text {exercise }}\right)$. Thus, this study gives further evidence that assessing the right heart size by imaging

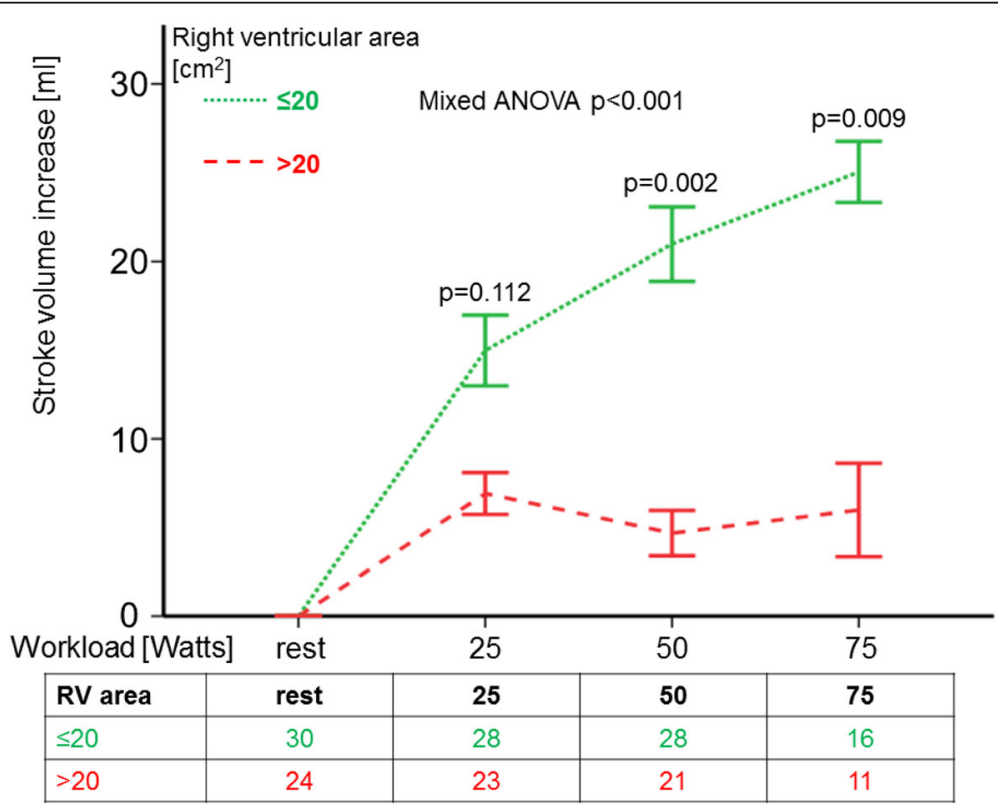

Fig. 3 Course of stroke volume increase during exercise according to RV area. Patients with smaller ( $\leq$ median $20 \mathrm{~cm}^{2}$, dotted line) RV area showed significantly higher SV increase during exercise, than patients with larger RV area (> median $20 \mathrm{~cm}^{2}$; dashed line; mixed ANOVA p < 0.001). Bars indicate the standard errors of the mean difference 

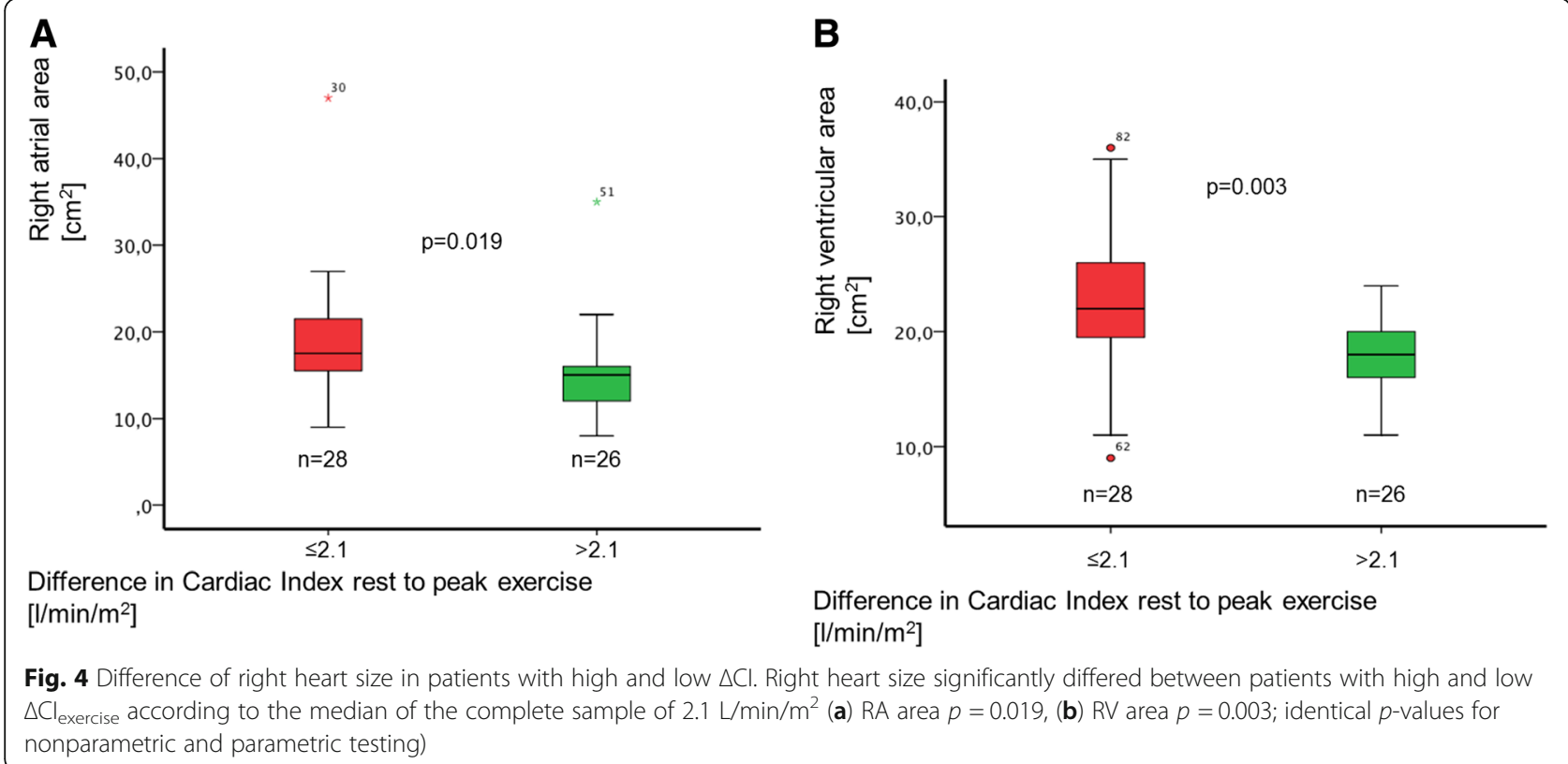

Fig. 4 Difference of right heart size in patients with high and low $\Delta \mathrm{Cl}$. Right heart size significantly differed between patients with high and low $\Delta \mathrm{Cl}_{\text {exercise }}$ according to the median of the complete sample of $2.1 \mathrm{~L} / \mathrm{min} / \mathrm{m}^{2}$ (a) RA area $p=0.019$, (b) RV area $p=0.003$; identical $p$-values for nonparametric and parametric testing)

techniques as echocardiography gives further important clues to RV pump function and cardiopulmonary hemodynamics.

\section{Right heart size, pump function}

This study confirms the results of previous studies using MRI which showed that enlarged RV end systolic and end-diastolic volumes were obtained in patients with lower RV stroke volumes [12, 26]. However, in the first previous MRI-study RV volumes were not directly compared with pump function but with survival [26]. Large RV end-diastolic volume and SV at baseline were associated with poorer prognosis. Further dilation of RV with further decrease of SV during follow-up predicted a poor long-term outcome [26]. Most recently these findings have been confirmed by an analysis of the French PAH registry demonstrating that SVI and right atrial pressure were independently associated with death or lung transplantation at first follow-up after initial PAH treatment [27].

Our study demonstrates for the first time a negative relationship between right heart size and RV pump function using 2-D-echocardiography for assessing the RA- and RV-areas in the four chamber view and hemodynamic values from right heart catheterization at rest and during exercise. Patients with enlarged RV area had significantly lower CI and SVI at rest and during exercise. These patients had also higher mean pulmonary arterial pressure, pulmonary vascular resistance at rest and NT-proBNP levels which reflects a more severe disease. The negative impact of RV-enlargement was also demonstrated by a MRI-study which showed in patients with increasing RV volumes during follow-up a disease progression leading to death or transplantation whereas patients with stable RV volumes remained clinically stable [12]. Changes in RV volumes were even more sensitive parameters for deterioration than the repeated measurement of hemodynamics which remained unchanged [12]. In this study, patients with enlargement of RV volumes had a decline of RV ejection fraction [12]. Two further studies demonstrated a reduction in $\mathrm{RV}$ volumes by targeted PAH-therapy, which suggests an improvement of RV pump function [11,28].

\section{RV output reserve and right heart size}

RV output reserve, defined in this study as increase of CI during exercise measured by right heart catheterization, is an emerging parameter which has shown to be of prognostic importance in patients with PH $[13,14]$. In this study RV area was identified as the only independent predictor of RV output reserve. This again shows that RV size may reflect the impairment of RV pump function. We hypothesize that increased PAC and reduced increase of RV output during exercise in patients with larger RV and/or RA areas, respectively is due to more severe pulmonary vascular disease. A both reproducible and clinically practical way to evaluate RV output reserve can be performed by invasive measurements ${ }^{15}$. Further prospective studies have to be conducted to evaluate the magnitude of the relation to right heart size and if non/ invasive assessment of RA- and RV area or volume are useful for an estimation of RV output reserve. 
Table 3 Correlation analysis of right heart size and clinical parameters

\begin{tabular}{|c|c|c|c|c|c|c|c|c|}
\hline & \multicolumn{4}{|c|}{ Right atrial area } & \multicolumn{4}{|c|}{ Right ventricular area } \\
\hline & $\bar{n}$ & pearson's R & $p$-value & & $\bar{n}$ & pearson's R & $p$-value & \\
\hline \multicolumn{9}{|l|}{ Univariate analysis } \\
\hline Age & 54 & 0.193 & 0.162 & & 54 & -0.048 & 0.209 & \\
\hline Body mass index & 54 & 0.181 & 0.190 & & 54 & 0.733 & 0.129 & \\
\hline 6-min walking distance & 53 & -0.108 & 0.441 & & 53 & -0.121 & 0.387 & \\
\hline NT-proBNP & 53 & 0.539 & $<0.001$ & * & 53 & 0.538 & $<0.001$ & * \\
\hline \multicolumn{9}{|l|}{ Echocardiography } \\
\hline Systolic pulmonary arterial pressure & 54 & 0.307 & 0.024 & * & 54 & 0.567 & $<0.001$ & * \\
\hline Right atrial area & & - & & & 54 & 0.703 & $<0.001$ & * \\
\hline Right ventricular area & 54 & 0.703 & $<0.001$ & * & & - & & \\
\hline Tricuspid annular plane systolic excursion & 54 & -0.128 & 0.356 & & 54 & -0.082 & 0.554 & \\
\hline \multicolumn{9}{|l|}{ Cardiopulmonary exercise testing } \\
\hline Peak oxygen consumption $\left(\mathrm{V}^{\prime} \mathrm{O}_{2}\right)$ & 54 & 0.042 & 0.736 & & 54 & 0.051 & 0.713 & \\
\hline Peak oxygen consumption/kg $\left(\mathrm{V}^{\prime} \mathrm{O}_{2} / \mathrm{kg}\right)$ & 54 & -0.199 & 0.149 & & 54 & -0.227 & 0.099 & \\
\hline \multicolumn{9}{|l|}{ Right heart catheter } \\
\hline \multicolumn{9}{|l|}{ rest } \\
\hline Mean pulmonary arterial pressure & 54 & 0.176 & 0.202 & & 54 & 0.544 & $<0.001$ & * \\
\hline Cardiac Output & 54 & -0.028 & 0.839 & & 54 & -0.052 & 0.709 & \\
\hline Cardiac Index & 54 & -0.209 & 0.129 & & 54 & -0.281 & 0.040 & * \\
\hline Pulmonary arterial wedge pressure & 54 & 0.025 & 0.857 & & 54 & -0.101 & 0.467 & \\
\hline Pulmonary vascular resistance & 54 & 0.175 & 0.206 & & 54 & 0.508 & $<0.001$ & * \\
\hline Stroke volume index & 54 & -0.244 & 0.076 & & 54 & -0.301 & 0.027 & * \\
\hline \multicolumn{9}{|l|}{ exercise } \\
\hline Mean pulmonary arterial pressure & 54 & 0.097 & 0.486 & & 54 & 0.419 & 0.002 & * \\
\hline Cardiac Output & 54 & -0.177 & 0.200 & & 54 & -0.223 & 0.104 & \\
\hline Cardiac Index & 54 & -0.344 & 0.011 & * & 54 & -0.427 & 0.001 & * \\
\hline$\triangle \mathrm{Cl}$ peak & 54 & -0.313 & 0.021 & * & 54 & -0.376 & 0.005 & * \\
\hline Stroke volume index & 54 & -0.264 & 0.054 & & 54 & -0.407 & 0.002 & * \\
\hline \multicolumn{9}{|l|}{ Lung function / Diffusing capacity } \\
\hline DLCOC SB & 48 & -0.052 & 0.723 & & 48 & -0.003 & 0.982 & \\
\hline DLCOC NA & 48 & 0.176 & 0.231 & & 48 & 0.137 & 0.352 & \\
\hline
\end{tabular}

$\mathrm{Cl}=$ Cardiac Index,$N T$-proBNP $=\mathrm{N}$-terminal pro brain natriuretic peptide, $D L C O c S B=$ diffusion capacity transfer factor, $D L C O c N A=$ diffusion capacity transfer coefficient

* = significant at level 0.05

Advanced PAH with increased pulmonary load leads to RV dilatation (heterometric adaptation) in order to maintain $\mathrm{SV}^{6}$. In this study $\mathrm{RV}$ output reserve was significantly linked to RV size.

\section{Study limitations}

The retrospective, single-center design of this study with a rather small number of subjects limits the study results. A higher sample size may have led to identification of more independent factors in the multivariate analysis.
Echocardiographic assessments of the right heart are complicated by its complex shape and morphology. Especially in obese patients, patients with chest wall deformities or COPD, the correct assessment of RV size and function becomes a challenging task. In this respect, cardiac MRI becomes particularly appealing, as it does provide a thorough assessment of right heart size and function even in complicated conditions. In our cohort, high quality recordings were used and no comorbidities were interfering the test results. As the determination of RA and RV area is a readily available 
Table 4 Uni- and multivariate regression analysis of RV output reserve

\begin{tabular}{|c|c|c|c|c|}
\hline Univariate analysis ( $\left.\triangle \mathrm{Cl}_{\text {Peak }}\right)$ & $\mathrm{n}$ & pearson's R & $p$-value & \\
\hline Age & 54 & 0.424 & 0.001 & * \\
\hline Body mass index & 54 & 0.092 & 0.506 & \\
\hline 6 min walking distance & 54 & 0.278 & 0.044 & * \\
\hline NT-proBNP & 54 & -0.360 & 0.008 & * \\
\hline \multicolumn{5}{|l|}{ Echocardiography } \\
\hline Systolic pulmonary arterial pressure & 54 & -0.462 & $<0.001$ & * \\
\hline Right atrial area & 54 & -0.313 & 0.021 & * \\
\hline Right ventricular area & 54 & -0.376 & 0.005 & * \\
\hline Tricuspid annular plane systolic excursion & 54 & 0.065 & 0.64 & \\
\hline \multicolumn{5}{|l|}{ Cardiopulmonary exercise testing } \\
\hline peak oxygen consumption $\left(\mathrm{V}^{\prime} \mathrm{O}_{2}\right)$ & 54 & 0.466 & $<0.001$ & * \\
\hline peak oxygen consumption/kg $\left(\mathrm{V}^{\prime} \mathrm{O}_{2} / \mathrm{kg}\right)$ & 54 & 0.380 & 0.005 & * \\
\hline \multicolumn{5}{|l|}{ Right heart catheter } \\
\hline \multicolumn{5}{|l|}{ rest } \\
\hline mean pulmonary arterial pressure & 54 & -0.288 & 0.035 & * \\
\hline Cardiac Output & 54 & 0.282 & 0.039 & * \\
\hline Cardiac Index & 54 & 0.223 & 0.106 & \\
\hline Pulmonary arterial wedge pressure & 54 & -0.016 & 0.906 & \\
\hline pulmonary vascular resistance & 54 & -0.366 & 0.006 & * \\
\hline \multicolumn{5}{|l|}{ exercise } \\
\hline mean pulmonary arterial pressure & 54 & -0.073 & 0.598 & \\
\hline Cardiac Output & 54 & 0.839 & $<0.001$ & * \\
\hline Cardiac Index & 54 & 0.894 & $<0.001$ & * \\
\hline \multicolumn{5}{|l|}{ Lung function / Diffusing capacity } \\
\hline DLCOc SB & 48 & 0.361 & 0.012 & * \\
\hline DLCOC / VA & 48 & 0.342 & 0.017 & * \\
\hline \multicolumn{5}{|l|}{ Multivariate analysis } \\
\hline \multicolumn{5}{|l|}{ Logistic Regression (stepwise forward selection) } \\
\hline$\Delta \mathrm{Cl}_{\text {exrcise (dichotomous) }}$ & & $\operatorname{Exp}(B)$ & & \\
\hline Right ventricular area & 47 & 0.863 & 0.027 & * \\
\hline \multicolumn{5}{|l|}{ Linear Regression (stepwise forward selection) } \\
\hline$\Delta \mathrm{Cl}_{\text {Peak (continuous) }}$ & & pearson's R & & \\
\hline Right ventricular area & 47 & -0.360 & 0.003 & * \\
\hline Age & 47 & -0.412 & 0.001 & * \\
\hline
\end{tabular}

$C l=$ Cardiac Index,$N T$-proBNP = N-terminal pro brain natriuretic peptide, $D L C O c S B=$ diffusing capacity transfer factor, $D L C O c / V A=$ diffusing capacity transfer coefficient

$*$ significant at level $0.05, \operatorname{Exp}(B)=$ Regression coefficient

assessment which is practicable in a good quality, its application in clinical practice is more common compared to cardiac MRI. Unfortunately, no MRI data is available for this patient cohort to confirm the hemodynamic data.

Invasive measurements, cardiopulmonary exercise testing and echocardiographic parameters could not be assessed in one single examination. In order to reduce the influence of inter-exam variations, we only included patients that underwent all measures within a time frame of $48 \mathrm{~h}$. The assessment of CI may be complicated by tricuspid insufficiency in patients with $\mathrm{PH}$. Due to the bidirectional blood flow through the tricuspid valve $\mathrm{CI}$ may be overestimated in some patients, which may have influenced the results.

The correlation of right heart size and function to TAPSE and other parameters and their prognostic value should be investigated in a larger-scale study. 


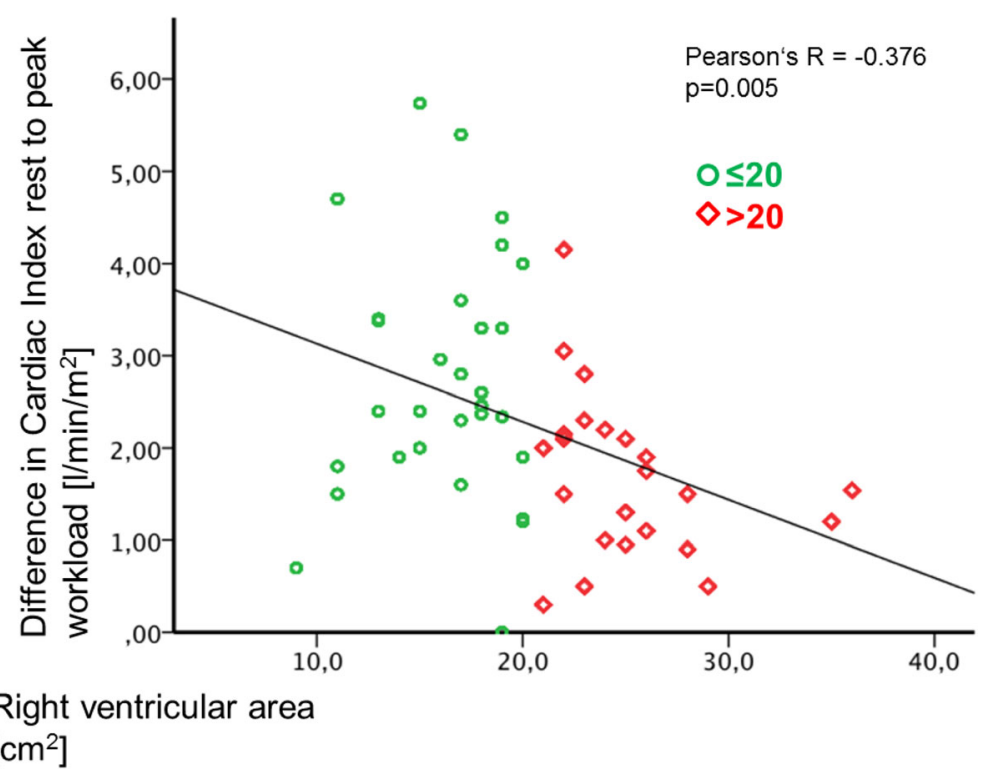

Figure 5 Correlation of RV-Area and $\Delta \mathrm{Cl}_{\text {exercise. }} \mathrm{RV}$ area showed a significant negative correlation with $\Delta \mathrm{Cl}_{\text {exercise }}(p=0.005)$

\section{Conclusion}

The study shows that assessment of right heart size is important for RV functional characterization and may be helpful since it reflects RV pump function and RV output reserve. RV and RA area by $2-\mathrm{D}$ echocardiography represented a valuable and easily accessible indicator of RV pump function at rest and during exercise. Therefore, these results may be relevant for clinical practice. RV output reserve should be considered as an important clinical parameter. However, prospective studies are needed for further evaluation.

\section{Abbreviations}

$\triangle$ : Difference; 6MWD: 6-min walking distance; ANOVA: Analysis of variance; APAH: Associated PAH; BMI: Body Mass Index; Cl: Cardiac Index; CO: Cardiac Output; CTEPH: Chronic thromboembolic pulmonary hypertension; DLCOc / VA: Diffusing capacity transfer coefficient; DLCOc SB: Diffusing capacity transfer factor; dPAP: Diastolic PAP; Exp (B): Regression coefficient; HPAH: Heritable PAH; HR: Heart rate; IPAH: Idiopathic pulmonary arterial hypertension; mPAP: Mean pulmonary arterial pressure; MRI: Magnetic resonance imaging; NT-proBNP: N-terminal pro brain natriuretic peptide; PAC: Pulmonary arterial compliance; PAH: Pulmonary arterial hypertension; PAP: Pulmonary arterial pressure; PASP: Pulmonary arterial systolic pressure; PCWP: Pulmonary capillary wedge pressure; PH: Pulmonary hypertension; PVR: Pulmonary vascular resistance; RA: Right atrial; RHC: Right heart catheter; RV: Right ventricular; SPAP: Systolic PAP; SV: Stroke volume; SVI: Stroke volume index; TAPSE: Tricuspid annular plane systolic excursion; TRV: Tricuspid regurgitation velocity; TTE: Transthoracic echocardiography; $\mathrm{VO}_{2}^{\prime}$ : Oxygen consumption

\section{Acknowledgements}

Not applicable.

\section{Funding}

No funding was received for this study.

\section{Availability of data and materials}

The datasets generated during and/or analysed during the current study are available from the corresponding author on reasonable request.
Authors' contributions

This work was the doctoral thesis of LF. EG, LF, CN, AMM, EB, NB, CF contributed substantially to the study conception and design. EG, LF, CN, BE, $\mathrm{SH}$ performed the assessments and patients examinations. LF, MK performed the data collection. NB, CF, LF performed the data analysis. All authors contributed to data interpretation and to the writing of the manuscript. All authors have read and approved the manuscript and agree to be accountable for all aspects of the work in ensuring that questions related to the accuracy or integrity of any part of the work are appropriately investigated and resolved.

\section{Ethics approval and consent to participate}

The Ethics Committee of the Medical Faculty, University of Heidelberg had no obligation against the conduct of the study (internal number S425/2016). All data were anonymized and the study was conducted in accordance with the amended Declaration of Helsinki.

\section{Consent for publication}

Not applicable.

\section{Competing interests}

LF nothing to disclose. NB received speaker honoraria and travel support from Actelion and Bayer outside the submitted work. BE nothing to disclose. $\mathrm{SH}$ received travel support from Actelion and OMT outside the submitted work. MK nothing to disclose. HML received consultancy / speaker fees from: AbbVie, Bristol-Myers Squibb, Roche-Chugai, UCB, MSD, GSK, Sobi, Medac, Novartis, Janssen-Cilag, AstraZeneca, Pfizer, Actelion; speakers bureau: AbbVie, Bristol-Myers Squibb, Roche-Chugai, UCB, MSD, GSK, Sobi, Medac, Novartis, Janssen-Cilag, AstraZeneca, Pfizer, Actelion outside the submitted work. NB received speaker honoraria from Actelion pharmaceuticals. AMM received grants from Italian Helthcare Ministry, grant for young researchers "Ricerca finalizzata 2016 per giovani ricercatori" n. GR-2016-02364727, personal lecture fee from Bayer Healthcare outside the submitted work; CN reports honoraria for lectures and participation in clinical trials from Actelion, Bayer/MSD, Novartis, speaker honoraria from Boehringer, Astra Zeneca, Berlin Chemie and participation in clinical trials from GSK, United Therapeutics outside the submitted work. CF nothing to disclose. EB nothing to disclose. EG received advisory board member and speaker honoraria from Actelion, Bayer/MSD, GSK, United Therapeutics, Novartis, Pfizer, OrphaSwiss GmbH outside the submitted work. 


\section{Publisher's Note}

Springer Nature remains neutral with regard to jurisdictional claims in published maps and institutional affiliations.

\section{Author details}

${ }^{1}$ Centre for Pulmonary Hypertension, Thoraxklinik at Heidelberg University Hospital, Röntgenstrasse 1, D-69126 Heidelberg, Germany. ${ }^{2}$ Translational Lung Research Center Heidelberg (TLRC), Member of the German Center for Lung Research (DZL), Heidelberg, Germany. ${ }^{3}$ Department of Rheumatology, University Hospital Heidelberg, Heidelberg, Germany. ${ }^{4}$ Institute of Human Genetics, University of Heidelberg, Heidelberg, Germany. ${ }^{5}$ RCCS SDN Research Institute, Naples, Italy. 6 Lung Centre, Klinikum Mittelbaden, Baden-Baden Balg, Baden-Baden, Germany. ${ }^{7}$ Heart Department, Cardiology Division, "Cava de' Tirreni and Amalfi Coast" Hospital, University of Salerno, Salerno, Italy.

Received: 2 August 2018 Accepted: 16 October 2018

Published online: 08 November 2018

\section{References}

1. D'Alonzo GE, Barst RJ, Ayres SM, et al. Survival in patients with primary pulmonary hypertension. Ann Intern Med. 1991;115(5):343-55.

2. Vonk-Noordegraaf A, Haddad F, Chin KM, et al. Right heart adaptation to pulmonary arterial hypertension: physiology and pathobiology. J Am Coll Cardiol. 2013;62(25):D22-33.

3. Amsallem M, Boulate $D$, Aymami M, et al. Load adaptability in patients with pulmonary arterial hypertension. Am J Cardiol. 2017;120(5):874-82.

4. Naeije R, Manes A. The right ventricle in pulmonary arterial hypertension. Eur Respir Rev. 2014;23(134):476-87.

5. Vanderpool RR, Pinsky MR, Naeije R, et al. RV-pulmonary arterial coupling predicts outcome in patients referred for pulmonary hypertension. Heart. 2015;101(1):37-43.

6. Vonk Noordegraaf $\mathrm{A}$, Westerhof $\mathrm{BE}$, Westerhof $\mathrm{N}$. The relationship between the right ventricle and its load in pulmonary hypertension. J Am Coll Cardiol. 2017:69(2):236-43.

7. Bustamante-Labarta M, Perrone S, De La Fuente RL, et al. Right atrial size and tricuspid regurgitation severity predict mortality or transplantation in primary pulmonary hypertension. J Am Soc Echocardiogr. 2002;15(10 2):1160-4.

8. Raymond RJ, Hinderliter AL, Willis PW, et al. Echocardiographic predictors of adverse outcomes in primary pulmonary hypertension. J Am Coll Cardiol. 2002;39(7):1214-9.

9. Grunig E, Henn P, D'Andrea A, et al. Reference values for and determinants of right atrial area in healthy adults by 2-dimensional echocardiography. Circ Cardiovasc imaging. 2013;6(1):117-24.

10. Austin C, Alassas K, Burger C, et al. Echocardiographic assessment of estimated right atrial pressure and size predicts mortality in pulmonary arterial hypertension. Chest. 2015;147(1):198-208.

11. van de Veerdonk MC, Huis In TVAE, Marcus JT, et al. Upfront combination therapy reduces right ventricular volumes in pulmonary arterial hypertension. Eur Respir J. 2017;49(6):1700007.

12. van de Veerdonk MC, Marcus JT, Westerhof N, et al. Signs of right ventricular deterioration in clinically stable patients with pulmonary arterial hypertension. Chest. 2015;147(4):1063-71.

13. Blumberg FC, Arzt M, Lange T, Schroll S, Pfeifer M, Wensel R. Impact of right ventricular reserve on exercise capacity and survival in patients with pulmonary hypertension. Eur J Heart Fail. 2013;15(7):771-5.

14. Chaouat A, Sitbon O, Mercy $M$, et al. Prognostic value of exercise pulmonary haemodynamics in pulmonary arterial hypertension. Eur Respir J. 2014:44(3):704-13.

15. Thenappan T, Prins KW, Pritzker MR, Scandurra J, Volmers K, Weir EK. The critical role of pulmonary arterial compliance in pulmonary hypertension. Ann Am Thorac Soc. 2016;13(2):276-84.

16. Jain $P$, Rao $S$, Macdonald $P$, et al. Diagnostic Performance of Pulmonary Capacitance at Rest and During Exercise in Idiopathic Pulmonary Arterial Hypertension. Heart Lung Circ. 2017. https://doi.org/10.1016/j.hlc.2017.10.019.

17. Galie N, Humbert M, Vachiery JL, et al. 2015 ESC/ERS guidelines for the diagnosis and treatment of pulmonary hypertension: the joint task force for the diagnosis and treatment of pulmonary hypertension of the European Society of Cardiology (ESC) and the European Respiratory Society (ERS): endorsed by: Association for European Paediatric and Congenital
Cardiology (AEPC), International Society for Heart and Lung Transplantation (ISHLT). Eur Heart J. 2016:37(1):67-119.

18. Guyatt GH, Pugsley SO, Sullivan MJ, et al. Effect of encouragement on walking test performance. Thorax. 1984;39(11):818-22.

19. Ehlken $\mathrm{N}$, Lichtblau $\mathrm{M}$, Klose $\mathrm{H}$, et al. Exercise training improves peak oxygen consumption and haemodynamics in patients with severe pulmonary arterial hypertension and inoperable chronic thrombo-embolic pulmonary hypertension: a prospective, randomized, controlled trial. Eur Heart J. 2016;37(1):35-44.

20. Kovacs G, Avian A, Olschewski A, Olschewski H. Zero reference level for right heart catheterisation. Eur Respir J. 2013;42(6):1586-94.

21. Kovacs G, Herve P, Barbera JA, et al. An official European Respiratory Society statement: pulmonary haemodynamics during exercise. Eur Respir J. 2017; 50(5):1700578.

22. Grunig E, Weissmann S, Ehlken N, et al. Stress Doppler echocardiography in relatives of patients with idiopathic and familial pulmonary arterial hypertension: results of a multicenter European analysis of pulmonary artery pressure response to exercise and hypoxia. Circulation. 2009;119(13):1747-57.

23. Rudski LG, Lai WW, Afilalo J, et al. Guidelines for the echocardiographic assessment of the right heart in adults: a report from the American Society of Echocardiography endorsed by the European Association of Echocardiography, a registered branch of the European Society of Cardiology, and the Canadian Society of Echocardiography. J Am Soc Echocardiogr. 2010;23(7):685-713 quiz 786-688.

24. Yock PG, Popp RL. Noninvasive estimation of right ventricular systolic pressure by Doppler ultrasound in patients with tricuspid regurgitation. Circulation. 1984;70(4):657-62.

25. Grunig E, Barner A, Bell M, et al. Non-invasive diagnosis of pulmonary hypertension: ESC/ERS guidelines with updated commentary of the Cologne consensus conference 2011. Int J Cardiol. 2011;154(1):S3-12.

26. van Wolferen SA, Marcus JT, Boonstra A, et al. Prognostic value of right ventricular mass, volume, and function in idiopathic pulmonary arterial hypertension. Eur Heart J. 2007:28(10):1250-7.

27. Weatherald J, Boucly A, Chemla D, et al. Prognostic value of follow-up hemodynamic variables after initial Management in Pulmonary Arterial Hypertension. Circulation. 2018;137(7):693-704.

28. Vanderpool RR, Desai AA, Knapp SM, et al. How prostacyclin therapy improves right ventricular function in pulmonary arterial hypertension. Eur Respir J. 2017:50(2):1700764.

\section{Ready to submit your research? Choose BMC and benefit from:}

- fast, convenient online submission

- thorough peer review by experienced researchers in your field

- rapid publication on acceptance

- support for research data, including large and complex data types

- gold Open Access which fosters wider collaboration and increased citations

- maximum visibility for your research: over $100 \mathrm{M}$ website views per year

At $\mathrm{BMC}$, research is always in progress.

Learn more biomedcentral.com/submission 